\title{
Rapid forgetting of social transmission of food preferences in aged rats: Relationship to hippocampal CREB activation
}

\author{
Renee A. Countryman ${ }^{1,3}$ and Paul E. Gold ${ }^{1,2,4}$ \\ ${ }^{1}$ Department of Psychology and Neuroscience Program, University of Illinois at Urbana-Champaign, Champaign, Illinois 61820, \\ USA; ${ }^{2}$ Department of Psychiatry and Institute for Genomic Biology, University of Illinois at Urbana-Champaign, \\ Champaign, Illinois 61820, USA
}

\begin{abstract}
A major characteristic of age-related changes in memory in rodents is an increase in the rate of forgetting of new information, even when tests given soon after training reveal intact memory. Interference with CREB functions similarly results in rapid decay of memory. Using quantitative immunocytochemistry, the present experiment examined the number of CREB- and PCREB-immunoreactive neurons in three regions of the dorsal and ventral hippocampus (dentate gyrus, CA3, and CAl) as a function of age and training. Rats were trained in a social transmission of food preference task. Using different food pairings, memory was tested in each rat immediately and $1,2,3$, and $7 \mathrm{~d}$ later. Both young and old rats had intact and comparable memory scores at the immediate and 24-h tests, but old rats exhibited more rapid forgetting thereafter relative to that of young rats. The main findings were that training resulted in large increases in the number of pCREB-immunoreactive cells throughout the hippocampus in both young and aged rats. However, particularly in the ventral hippocampus, the training-elicited increase in pCREB-positive neurons was significantly lower in old than in young rats. Based on Western blot analyses in a separate set of rats, CREB levels were not responsive to training but were lower in the ventral hippocampus of old rats than of young rats. The present findings suggest that lower activation of CREB after training may contribute to the rapid forgetting seen in aged rats.
\end{abstract}

Rats and mice exhibit age-related impairments in learning and memory on many tasks. Often, the impairments can be characterized in terms of rapid forgetting, in which aged rats and mice have relatively comparable learning and memory on tests soon after training, but poor memory at later times after training (Barnes and McNaughton 1985; Winocur 1988; Korol and Gold 1998; Foster 1999; Gold 2001; Korol 2002). There are many such examples of accelerated forgetting in aged rodents, with specific time courses that differ by task. Memory for inhibitory avoidance training, which remains stable for weeks after training in young rats, is intact only during the first few hours after training and then deteriorates over the next hours and days (Gold et al. 1982). Rapid forgetting is also evident in the swim task, in which learning within a day appears to be forgotten overnight by aged but not young rats (Gage et al. 1984; Rapp et al. 1987; Mabry et al. 1996). Similarly, young and aged rats have comparable memory scores on a reward reduction task when tested $1 \mathrm{~d}$ after training, but aged and not young rats exhibit forgetting when tested $7 \mathrm{~d}$ after training (Salinas and Gold 2005). Other examples include more rapid forgetting in aged than young rats and mice on visual discriminated avoidance (Gold et al. 1982), spatial (Barnes and McNaughton 1985), spatial reversal (Zornetzer et al. 1982), spontaneous alternation (Stone et al. 1992), odor-reward association (Roman et al. 1996), and eye-blink classical conditioning (Solomon et al. 1995) tasks.

Rapid forgetting seen during aging is analogous to similar findings seen after many treatments that interfere with cell and

${ }^{3}$ Present address: Illinois Wesleyan University, Department of Psychology, Bloomington, Illinois 61702, USA.

${ }^{4}$ Corresponding author.

E-mail pgold@uiuc.edu; fax (217) 244-5876.

Article is online at http://www.learnmem.org/cgi/doi/10.1101//m.524907. molecular processes associated with the formation of new memories. Rapidly decaying memory is seen after administration of protein synthesis inhibitors, ERK/MAPK inhibitors, and inhibitors of transcription factors, such as cAMP response elementbinding protein (CREB), and is also seen in several knockout and transgenic mice with alterations aimed at these and other molecular targets (e.g., Goelet et al. 1986; Yin and Tully 1996; Guzowski and McGaugh 1997; Silva et al. 1998; Houpt and Berlin 1999; Schulz et al. 1999; Guzowski et al. 2000; McGaugh 2000; Kandel 2001; Stanciu et al. 2001; Taubenfeld et al. 2001; Izquierdo et al. 2002; Kelly et al. 2003; Apergis-Schoute et al. 2005; Trifilieff et al. 2006); these findings are generally described as reflecting decay of short-term memory processes.

Of particular relevance to the present report, considerable evidence suggests that CREB is a transcription factor important to the formation of durable memories, perhaps converting rapidly decaying memories and short-term potentiation to more permanent forms (Dash et al. 1990; Impey et al. 1996, 1998; Silva et al. 1998; Schulz et al. 1999). For example, CREB knockout mice have intact memory for 30-60 min after training, but impaired memory $24 \mathrm{~h}$ or more after training (e.g., Kogan et al. 2000; Frankland et al. 2004). Also, after administration of CREB antisense into the hippocampus, rats exhibit intact memory up to $4 \mathrm{~h}$ after training, but impaired memory $48 \mathrm{~h}$ after training (Guzowski and McGaugh 1997). Similarly, overexpression in the hippocampus of a mutant form of CREB that interferes with CREB functions results in memory that is evident in rats tested at 30 min after training, but not at $11 \mathrm{~d}$ after training in a social transmission of food preference similar to that used in the present experiment (Brightwell et al. 2005).

The parallels between the rapid forgetting in these experiments and those seen in aged rodents suggest that similar cellular 


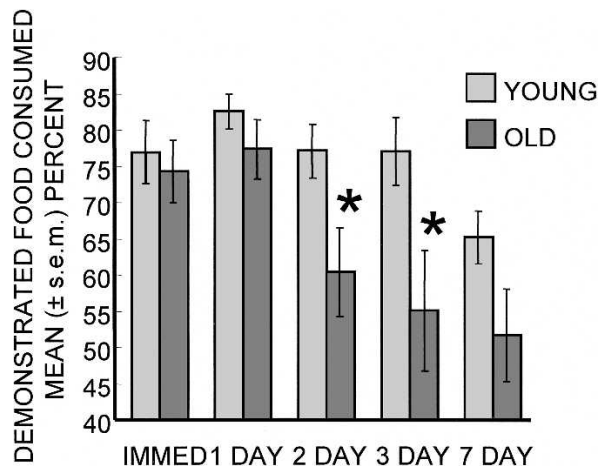

Figure 1. Demonstrated food consumed as percent of total food consumed during memory tests for young adult and aged rats. No evidence of preference would be $50 \%$. Note that aged rats forgot the socially transmitted food preference more rapidly than did young adult rats. $\left(^{*}\right) P<0.05$ young vs. old. At the 1 -wk interval, $P=0.09$.

mechanisms may contribute to rapid forgetting seen both after interference with molecular cascades involved in memory formation and in aged rats and mice. A few studies have examined CREB functions in aged rodents (cf. Lund et al. 2004). Aged rats display decreased basal forebrain and hippocampus CREB-DNA binding (Asanuma et al. 1996). Expression of phosphorylated CREB (pCREB) appears to be reduced in the hippocampus of aged rats (Foster et al. 2001; Brightwell et al. 2004; Kudo et al. 2005; but see also Monti et al. 2005). Also, aged rats with poor spatial memory have hippocampal CREB levels lower than those of aged rats with good spatial memory (Brightwell et al. 2004). Thus, age-related differences in the expression of CREB and pCREB may contribute to the rapid forgetting that is characteristic of aged rodents.

The present experiment examines forgetting and associated changes in CREB and PCREB in rats trained on a social transmission of food preference (STFP) task (Galef and Whiskin 2003). In this task, an observer rat is allowed to interact with a demonstrator rat that had recently eaten a novel food. After the social interaction, observer rats prefer the demonstrated food to a new food. Training in the STFP task results, in young rats, in phosphorylation of CREB in the hippocampus (Countryman et al. 2005). Memory in this task is sensitive to damage of several brain regions, including the hippocampus (Winocur and Moscovitch 1999; Alvarez et al. 2002; Clark et al. 2002; Roberts and Shapiro 2002; Ross and Eichenbaum 2006). Interestingly, hippocampal lesions prior to training lead to rapid forgetting in this task (Winocur 1990; Bunsey and Eichenbaum 1995; Winocur et al. 2001).

The findings of the present experiment show that aged rats forget the STFP task more rapidly than do young rats. In addition, although phosphorylation of CREB in response to training is evident in the hippocampus of both young and old rats, posttraining expression of PCREB increases significantly less in the ventral hippocampus of aged rats than that of young rats.

\section{Results}

\section{Forgetting rates in young and old rats}

Old rats exhibited faster forgetting after training than did young rats. As shown in Figure 1, both the young and aged rats showed significant preferences (scores $>50 \%$ ) for the demonstrated food when tested immediately after training. The preferences were maintained in both age groups at the 24-h test. At both the immediate and 24-h tests, the percent of demonstrated food eaten was comparable across the age groups (Ps > 0.2).
The retention curves diverged by age at later intervals between training and testing, with the young rats exhibiting stronger preferences than those of the aged rats for the demonstrated food at both 48 and $72 \mathrm{~h}$ after training ( $P$ s $<0.05)$. A similar trend remained after a 1 -wk training-testing interval $(P<0.1)$.

A repeated measures ANOVA revealed a significant effect of age $\left(F_{(1,17)}=8.04 ; P<0.02\right)$ and delay $\left(F_{(1,4)}=6.50 ; P<0.002\right)$. The interaction of delay $\times$ age was not statistically significant $\left(F_{(1,4)}=1.48 ; P>0.2\right)$, reflecting the forgetting that was evident in both groups, though forgetting was more rapid in the aged rats when analyzed by group comparisons as above.

Examination of memory across the aged rats revealed a high degree of individual variability as is often reported in aging experiments (cf. Gallagher and Rapp 1997). When tested at training-test intervals from immediate to $3 \mathrm{~d}$, no young rats showed forgetting, defined here as $<5 \%$ preference for the demonstrated food. At $7 \mathrm{~d}$, three young rats exhibited forgetting. When tested immediately after training, all aged rats showed a preference for the demonstrated food. The number of old rats exhibiting forgetting increased with time after training, from one at $24 \mathrm{~h}$, to four at 48 and $72 \mathrm{~h}$, to six of the nine rats tested at $1 \mathrm{wk}$. Importantly, this was not simple variability at each time point but represented accrual of the same rats exhibiting forgetting over time; the rats that showed forgetting at short training-testing intervals also showed forgetting at longer intervals.

\section{CREB- and pCREB-positive cells as a function of age and training}

The main findings were: (1) Counts of CREB-immunoreactive cells differed by age only in ventral hippocampus CA3. (2) Counts of pCREB-immunoreactive cells were higher in young than old rats in dorsal CA1 and ventral dentate gyrus under both trained and untrained conditions. (3) pCREB-, but not CREB-, immunoreactive cells increased with training in both young and old rats in most hippocampal regions tested. (4) In young versus old rats, training resulted in greater increases in pCREB-positive cells in ventral hippocampus dentate gyrus, CA3 and CA1, and in dorsal hippocampus CA1. Ratios of pCREB/CREB were also examined; these values added no significant information to the results apparent in the CREB and PCREB analyses and are therefore not reported here. Figure 2 shows representative photomicrographs demonstrating differences by age and training in pCREB immunoreactivity in ventral CA3.

\section{CREB}

As shown in Figure 3, the numbers of CREB-positive cells in the ventral hippocampus were generally comparable in CA1 and dentate gyrus samples across age and training conditions

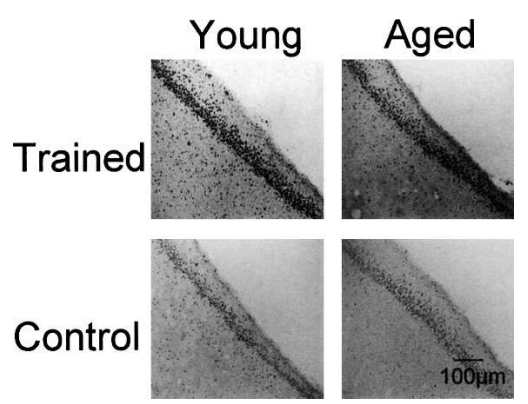

Figure 2. Photomicrographs representing $P C R E B$-immunostained cells in CA3 of untrained and trained, young and old rats. Note that training resulted in an increase in PCREB-immunoreactive cell numbers in both old and young rats. However, the magnitude of increase was greater in young than old rats. 
CREB - VENTRAL HIPPOCAMPUS

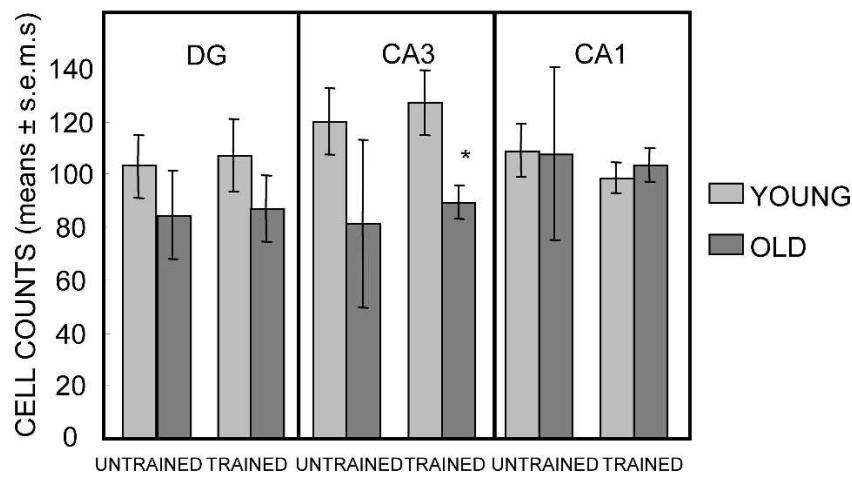

Figure 3. Counts of CREB-immunoreactive cells in the ventral hippocampus. There were fewer CREB-positive cells in CA3 in old than in young rats, without a differential effect of training. $\left(^{*}\right) P<0.05$ young vs. old.

(Ps $>0.1)$. However, young rats had a higher number of CREBpositive cells than did aged rats in the ventral CA3 measures. This difference was significant within the trained animals and overall by age $\left(F_{(1,28)}=8.92 ; P<0.01\right)$. CREB-positive cells in the dorsal hippocampus did not differ by age or training in any brain area tested (Fig. 4).

\section{pCREB}

The results obtained with counts of pCREB-positive cells in the ventral hippocampus are shown in Figure 5. The effect most evident in Figure 5 is that training resulted in dramatic increases in the number of pCREB-positive cells throughout the ventral hippocampus in both age groups (all $P \mathrm{~s}<0.05$ vs. respective untrained same-age controls). In untrained rats, there was a significant effect of age only in the dentate gyrus $\left(F_{(1,28)}=5.48\right.$; $P<0.05)$. Trained rats exhibited effects of age in all three sampling regions $(P s<0.05)$, with a significant interaction of age $\times$ training evident in CA1 $\left(F_{(1,28)}=4.51 ; P<0.05\right)$, a trend toward interaction in CA3 $\left(F_{(1,28)}=3.66 ; P<0.07\right)$, but no significant interaction in the dentate gyrus $\left(F_{(1,28)}=2.57 ; P<0.2\right)$.

The dorsal hippocampus results for pCREB-positive cell counts are shown in Figure 6. As in the ventral hippocampus, the dorsal hippocampus showed large increases in the number of pCREB-positive cells in CA3 and CA1 in both young and aged rats (all $P$ s $<0.001$ vs. respective untrained same-age controls) but, in contrast to the results obtained in the other regions sampled, the number of pCREB-positive cells in the dorsal hippocampus dentate gyrus did not increase in response to training (PS $>0.1)$. In the dorsal hippocampus of untrained rats, there was a significant effect of age only in CA1 $\left(\mathrm{F}_{1,32}=176.83, P<0.001\right)$; this effect was evident in both untrained and trained rats $(P s<0.05)$.

\section{Western blot analyses of age- and training-related differences in expression of CREB in the hippocampus}

The results of the Western blot analyses are shown in Figure 7. Aged rats, whether trained or not, had significantly lower levels of CREB protein in the ventral hippocampus than did young rats $(P s<0.05)$. CREB levels did not differ by training condition in either young or old rats $(P \mathrm{~s}>0.5)$. There were no differences in CREB levels in the dorsal hippocampus as a function of either age or training ( $P S>0.5)$.

These findings match the cell counts described above, with the Western blot results showing lower CREB levels in the ventral hippocampus of aged versus young rats, but similar levels in the dorsal hippocampus. The immunocytochemistry described ear- lier suggests that the age-related decrease in CREB levels in the ventral hippocampus is largely the result of decreases in CA3.

Multiple correlations were performed to determine whether total CREB protein levels in the dorsal and/or ventral hippocampus of either aged or young rats were correlated with memory at any of the training-testing delays tested. No significant correlations were observed (data not shown).

\section{Discussion}

The behavioral findings of these experiments show that young and old rats acquire and remember the odor demonstrated during STFP training about equally for up to $24 \mathrm{~h}$. The similar performance at these times suggests that performance variables, such as decreased sensory acuity, locomotor activity, or engagement in social interaction, do not account for the differences at later time points after training. Beyond $24 \mathrm{~h}$, old rats exhibit poor memory when compared with that of young rats. Thus, this task adds to those on which rapid forgetting is a key characteristic of age-related changes in memory (Barnes 1979; Barnes and McNaughton 1985; Winocur 1988; Korol and Gold 1998; Gold 2001, 2005; Korol 2002). Many experiments examine individual differences in memory in aged rodents by identifying memoryimpaired versus unimpaired rats at single time points, often in the swim task (Gallagher and Nicolle 1993; Gallagher et al. 1993; Gallagher and Rapp 1997). However, the memory-impaired rats identified with this method of assessment are not always matched by impairments on other tasks (Markowska et al. 1989; Lamberty and Gower 1992; Gower and Lamberty 1993). Perhaps individual differences would be more coherent across tasks if the rates of forgetting were examined, as compared with the more usual single memory tests at a fixed time after training. The social transmission task, as used here with repeated training and variable test intervals, enables identification of individual differences in rates of forgetting. As seen in the growing number of old rats exhibiting forgetting at different intervals after training, there is also considerable spread of forgetting rates across the rats.

Thus, the findings that old rats exhibit rapid forgetting suggest that the rate of forgetting, rather than memory at any one time after training, may be a useful approach with which to sort rats with and without age-related memory impairments. A demonstration of the utility of forgetting rates to identify individual differences in aged rats was seen in an early study on aging and memory in rats (Barnes and McNaughton 1985) in which the rate of forgetting after training on the Barnes circular platform was correlated with the rate of decay of long-term potentiation (LTP). Importantly, in that experiment the actual rates of forgetting and LTP decay were quite different but were rank-ordered similarly

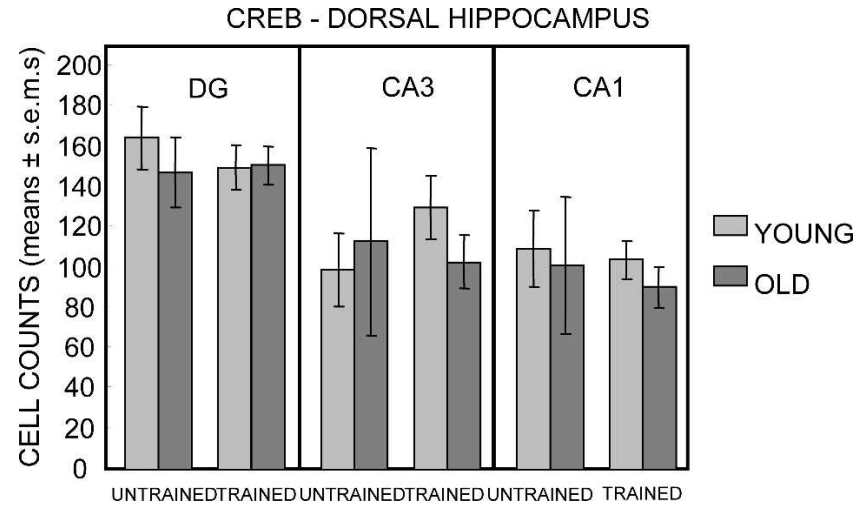

Figure 4. Counts of CREB-immunoreactive cells in the dorsal hippocampus. There were no significant differences in the number of CREBpositive cells by age or by training status. 
PCREB - VENTRAL HIPPOCAMPUS

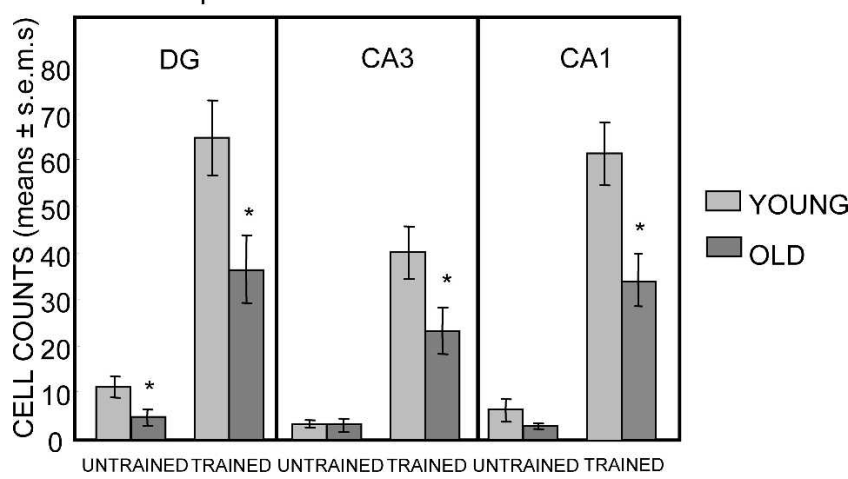

Figure 5. Counts of pCREB-immunoreactive cells in the ventral hippocampus. Note that training elicited large increases in pCREB-positive cells in both young and old rats; all training-related increases were statistically significant for both young and old rats. In all three regions of the ventral hippocampus, the post-training numbers of pCREB-positive cells were higher in young than in old rats. $\left(^{*}\right) P<0.05$. Only the dentate gyrus exhibited fewer PCREB-positive cells in untrained old vs. young rats.

across the aged rats tested. Thus, there was significant correspondence of the rates of forgetting and decay across memory and neural plasticity measures, a relationship that might not be evident if single time points were used to assess impairments of memory and LTP.

The number of cells positive for pCREB, but not CREB, increased dramatically after training in both young and old rats throughout most of the hippocampus. These findings are consistent with past results showing pCREB responses to training in a STFP task (Countryman et al. 2005). In that report, the increase in pCREB-positive cells was generally greater in trained rats than in several controls for social or odor experiences. The major agerelated changes in the immunocytochemistry measures in the present study were the greater training-related increases in pCREB-positive cells in young than in aged rats, especially in the ventral hippocampus. The greater increase of pCREB-positive cells in the ventral hippocampus than in dorsal hippocampus is consistent with past findings in young adult rats (Countryman et al. 2005). Using lesion analyses, damage to the dorsal or ventral hippocampus, or both, impairs learning and memory of the social transmission of food preference (Winocur 1990; Bunsey and Eichenbaum 1995; Winocur et al. 2001; Alvarez et al. 2002; but see also Burton et al. 2000). The larger training-related increases in pCREB levels seen here in the ventral hippocampus may reflect the involvement of the ventral hippocampus in circuits important for ingestive behaviors (Petrovich et al. 2001).

pCREB levels in untrained rats were somewhat higher in CA1 of the dorsal hippocampus and in the dentate gyrus of the ventral hippocampus in young rats than in old rats. CREB measures, by counts of CREB-positive cells and by total protein, did not differ substantially by age or by training in the dorsal hippocampus but were lower in the ventral hippocampus. The findings in the dorsal hippocampus that the number of CREBimmunoreactive cells did not differ by age and that pCREBimmunoreactive cells increased less in aged than in young rats are both consistent with results obtained in dorsal CA1 of rats after footshock in a contextual fear conditioning task (Kudo et al. 2005).

In the present experiment, the principal effects of age and training were in the activation status of CREB, rather than in the protein levels. In particular, it is the decrease in pCREB-positive cells in aged rats after training that may be associated with agerelated changes in memory. Because constitutively expressed CREB is comparable across ages, mechanisms upstream of CREB activation may represent the primary deficit. While the bases for the decreased pCREB responses to training in aged rats are not clear, possible mechanisms include dysregulation of calcium fluxes (e.g., Disterhoft et al. 1994; Thibault et al. 1998; Foster et al. 2001) and neurotransmitter and receptor functions, including NMDA receptor changes with age (Wenk and Barnes 2000), cholinergic coupling to CREB (Dineley et al. 2001). More broadly, the age-related decrease in activation of CREB may be general to many signals and to cells in non-neural as well as neural tissues (e.g., Kunieda et al. 2006). Further, the primary dysfunctions may lie within the elements of the signaling cascades leading to activation of CREB.

Interference with CREB functions often results in rapid rates of forgetting in young rats and mice (Guzowski and McGaugh 1997; Kogan et al. 2000; Frankland et al. 2004; Brightwell et al. 2005 ) that seem generally analogous to the rapid forgetting seen in aged rats. But, the analogy also has an apparent inconsistency between studies of CREB-deficient young animals and the old animals tested here. Specifically, the time courses for decay of memory in studies of young rats and mice with impaired CREB functions are typically on the order of several hours, a time frame considerably shorter than the $24-48 \mathrm{~h}$ at which forgetting appeared in aged rats in the present experiment. However, there are several factors that address this issue. First, few studies have carefully examined the time courses of forgetting under conditions of impaired CREB functions. It is possible that the time courses of forgetting in CREB-deficient rats and mice may be quite variable by task and other variables, as they are for protein synthesis inhibitors (cf. Gold 2006). For example, in studies using cycloheximide or anisomycin to inhibit protein synthesis, the range of times to onset of amnesia range from $\sim 1 \mathrm{~h}$ to $24 \mathrm{~h}$ for memory (Quartermain and McEwen 1970; Squire and Barondes 1972) and for decay of long-term potentiation range from $\sim 10 \mathrm{~min}$ to $4 \mathrm{~h}$ (Huang et al. 1994; Tang et al. 1999; cf. Gold 2006). Thus, the time course of decay is not fixed under many other conditions and it seems possible that similar variability will be evident with more extensive tests of CREB dysfunction. With specific regard to social transmission of food preference, there appears to be rapid forgetting in CREB mutant mice (Kogan et al. 1996). However, in that study, memory was intact on an immediate test and impaired on a test at $24 \mathrm{~h}$; intermediate times were not assessed, thereby leaving unclear the rate of forgetting of the social transmission of food preference in the CREB mutant mice. In addition, the exposure time to the demonstrator was $10 \mathrm{~min}$ (two

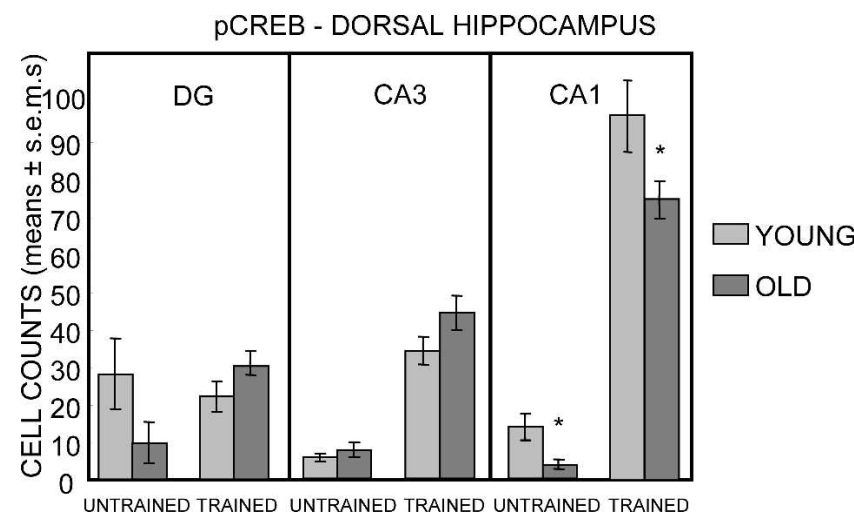

Figure 6. Counts of $p C R E B$-immunoreactive cells in the dorsal hippocampus. As in ventral hippocampus, training elicited a large increase in pCREB-positive cells in both young and old rats in CA3 and CA1. However, a training-related increase was not evident in the dentate gyrus of either young or old rats. The numbers of pCREB-positive cells in CA1 were higher in young than in old rats under both untrained and trained conditions. $\left(^{*}\right) P<0.05$. 


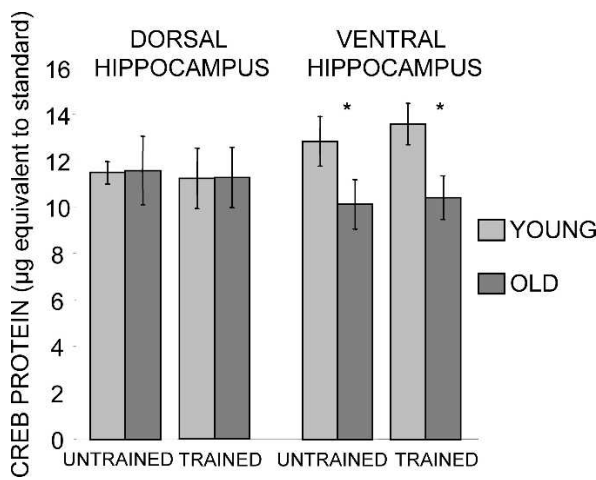

Figure 7. Total CREB protein milligram equivalent to standards for the dorsal and ventral hippocampus of trained and control rats (means \pm SEM). Note that aged rats had significantly lower levels of total CREB protein in the ventral hippocampus than did young rats. $\left({ }^{*}\right) P<0.05$. No effects of training on CREB protein levels were evident.

5-min exposures with a 1-min interval between them) in the study with CREB mutant mice versus the continuous 30-min exposure here. It seems likely that the rate of forgetting will be a function of the amount of training. An extension of this view is that graded cellular events after training, such as phosphorylation of CREB, may set the conditions for decay of memory in addition to or rather than the conditions for formation of memory.

A second factor may also be important for understanding the relationship between the forgetting time course across days, rather than hours, in aged rats and the decreased levels of pCREB in aged rats. While training-related phosphorylation of CREB was impaired in aged rats, training-induced increases in phosphorylation of CREB were nonetheless readily apparent in the ventral hippocampus of aged rats. Thus, partial impairment of the phosphorylation of CREB may result in more rapid forgetting than if phosphorylation were intact, but slower forgetting than if pCREB were nearly completely eliminated. In this sense, the present findings may be similar to results showing that gene dosage is a key element of memory impairments seen in mice with CREB mutations (Gass et al. 1998).

Findings from studies of rats with hippocampal lesions may also bear on the relatively rapid forgetting seen in old as compared with young rats. In particular, Winocur et al. (2001) examined the rate of forgetting for social transmission of food preference in rats with lesions of the hippocampus. The findings of this experiment revealed more rapid forgetting in the lesioned rats than in controls, but this was particularly evident beginning several days after training. Perhaps the slow forgetting under conditions of diminished levels of pCREB reflects a function of the hippocampus in regulating the rate of forgetting, a function for which decreases in training-induced expression of pCREB mark the dysfunction of the hippocampus. The extent to which the magnitude and duration of phosphorylation of CREB might contribute to age-related accelerated forgetting will require comparisons of the timing of training-associated pCREB expression in young and old rats, and in aged rats that have rapid or slow forgetting rates.

A few studies have examined the expression of pCREB and other transcription factors a day or more after training. In addition to training-related increases in PCREB that are evident soon after training, there is evidence for longer lasting increases in expression of pCREB. Phosphorylation of CREB appears to follow a biphasic temporal pattern in the hippocampus after induction of long-term potentiation, training, or administration of a stressor, with an early peak followed several hours later by a second peak (Bernabeu et al. 1997; Schulz et al. 1999; Stanciu et al. 2001; Bilang-Bleuel et al. 2002). Also, CREB phosphorylation can remain up-regulated for more than $24-48 \mathrm{~h}$ after long-term potentiation or training (Schulz et al. 1999; Taubenfeld et al. 2001; Bilang-Bleuel et al. 2002; Trifilieff et al. 2006). Similarly, protein levels of the transcription factors c-Fos and Zif268 are also elevated for at least $24 \mathrm{~h}$ after inhibitory avoidance training; moreover, treatments that impair memory also impair the increases in c-Fos and Zif268 seen at $24 \mathrm{~h}$ after training (Bekinschtein et al. 2007). These findings raise the possibility that there are training-related increases in pCREB and other transcription factors that long outlast the experience and that may be important in regulating and maintaining memory for a considerable time after training. In the present experiment, pCREB was assessed only after a single 1-h delay after training. These diminished pCREB levels seen in aged rats soon after training might predict such changes at $24 \mathrm{~h}$ or more after training. The extent to which the magnitude and duration of phosphorylation of CREB might contribute to age-related accelerated forgetting will require comparisons of the timing of training-associated pCREB expression in young and old rats along with the differential rates of forgetting in these rats.

In summary, the present findings show that forgetting of memory for a socially transmitted food preference is more rapid in old than in young rats. In addition, there is a parallel decrease with age in the number of pCREB-positive cells seen after training. With the considerable evidence that activation of CREB at the time of training is important for the maintenance of the learned response, the present results point to a potential relationship between activation of CREB in the hippocampus and rate of forgetting for the STFP task.

\section{Materials and Methods}

\section{Subjects}

One set of young ( $3 \mathrm{mo} ; N=10$ ) and old (32 mo; $N=9$ ) male Fischer $344 \times$ Brown Norway $F_{1}$ hybrid rats, acquired from NIA, was used in the main behavioral experiment. These rats were also included in the Western blot analyses, with the addition of untrained controls (young and old, $N s=7$ ). An additional set of rats (young and old, trained and untrained; $N s=10$ ) was used for immunocytochemistry measures.

Rats were individually housed in plastic-bottom cages in a humidity- and temperature-controlled environment with a 12-h light/dark cycle (lights on at 07:00 h) and with ad libitum access to food and water except as noted behavioral procedures. Beginning 1 wk after arrival at our facility, the rats were handled daily for $5 \mathrm{~min} / \mathrm{d}$ for $7 \mathrm{~d}$. All behavioral testing was conducted during the light phase of the cycle.

All procedures were approved by the University of Illinois Institutional Animal Care and Use Committee, were conducted in accordance with the National Institutes of Health Guide for the Care and Use of Laboratory Animals, and complied with the National Institutes of Health guidelines for animal care and use.

\section{Social transmission of food preference training}

Five days prior to being transferred to the interaction cages, both observer and demonstrator rats were placed on a $22 \mathrm{~h} / \mathrm{d}$ food deprivation schedule. Prior to training, observer and demonstrator rat dyads were placed into opposite sides of a $42 \times 24 \times 27$ $\mathrm{cm}$ plastic-bottom interaction cage with sawdust bedding and a wire mesh $(1 \times 1-\mathrm{cm}$ openings $)$ screen in the middle. During this preconditioning phase, rat dyads were left undisturbed for $2 \mathrm{~d}$ with unlimited access to standard rat chow and water. On day 3 , all food was removed from the cages. Training was conducted after $22 \mathrm{~h}$ of food deprivation.

For STFP training, the demonstrator rat was removed from the interaction cage and taken to a separate room where it was 
Table 1. Food pairs used for innate food preference tests and training

\begin{tabular}{llc}
\hline Training-test interval & \multicolumn{1}{c}{ Demonstrated } & Novel \\
\hline 7 days & $1.1 \%$ Coriander & $0.8 \%$ Marjoram \\
3 days & $0.8 \%$ Cumin & $1 \%$ Oregano \\
2 days & $1 \%$ Cocoa $+2 \%$ Sucrose & $1 \%$ Cinnamon \\
1 day & $1.2 \%$ Nutmeg & $0.8 \%$ Ginger \\
Immediate & $1 \%$ Thyme & $1 \%$ Turmeric \\
\hline
\end{tabular}

allowed to eat for $30 \mathrm{~min}$ from a food cup containing $10 \mathrm{~g}$ of ground chow mixed with a commercially ground spice. Demonstrator rats were then returned to the interaction cages to interact with the observer rats for $30 \mathrm{~min}$ through the wire-mesh partition.

Except for the immediate memory tests, observer rats were returned after training to their home cages with ad libitum food and water for a variable delay (1-wk, 72-h, 48-h, 24-h) prior to the recall test for food preference. Between training and memory tests with these delays, food was returned to the home cage and was then removed $22 \mathrm{~h}$ prior to the recall test. Each rat was trained on each of five food pairs as shown in Table 1 . These pairs and specific flavor concentrations were based on pilot data indicating that rats sampled the items of each pair approximately equally in the absence of STFP training. First, rats were trained and then tested $7 \mathrm{~d}$ later for food preference memory. Next, rats were trained on the second food pairing and were tested $72 \mathrm{~h}$ later, followed similarly by 48 -h recall, 24 -h recall, and immediate tests.

For the memory tests, observer rats were placed into a $42 \times 24 \times 27$-cm plastic-bottom cage in which two food cups containing $15 \mathrm{~g}$ of either the demonstrated food or the novelflavored rat chow were affixed to opposite ends of the cage. A small ledge in the center of the cage was used to prevent food from mixing. Rats were placed into the cage so that they were straddling the ledge, facing a wall. The rats were allowed to eat from the food cups for $1 \mathrm{~h}$. The amount of each remaining food was weighed, and the amount of each flavored food consumed during test was determined. The behavioral measure was the percent of total food consumed for the demonstrated food: [demonstrated food consumed $(\mathrm{g}) /$ total food consumed $(\mathrm{g})] \times 100$.

\section{Immunocytochemistry}

\section{Tissue preparation}

Immediately following the final (immediate) test for food preference, trained rats (10 trained young, 10 trained aged), along with eight untrained young and eight untrained old rats, were deeply anesthetized with sodium pentobarbital. Rats were perfused transcardially with $2 \%$ sodium nitrate in saline, followed by $4 \%$ paraformaldehyde in $0.1 \mathrm{M}$ phosphate buffered saline (PBS). Brains were removed and post-fixed in $4 \%$ paraformaldehyde overnight and then transferred to a $20 \%$ sucrose/phosphate buffer solution at $4^{\circ} \mathrm{C}$ until they were sectioned in a cryostat. Coronal sections $(50 \mu \mathrm{m})$ beginning at $-3.0 \mathrm{~mm}$ relative to bregma and ending at $-6.0 \mathrm{~mm}$ relative to bregma were collected in cryoprotectant (30\% ethylene glycol, 30\% sucrose, 1\% polyvinylpyrrolidone $40 \mathrm{kDa}$ in phosphate buffer) and frozen at $-20^{\circ} \mathrm{C}$ until immunoassays were performed.

\section{Immunocytochemistry procedures}

Using 24-mm net-wells (Corning), sections were washed four times in $0.05 \mathrm{M}$ PBS before a peroxidase block (1\% normal goat serum [NGS], $0.02 \%$ Triton-X [TX], 1\% hydrogen peroxide solution in PBS for $10 \mathrm{~min}$ ) was used to inhibit endogenous peroxidases. Sections were then washed for $15 \mathrm{~min}$ in a $\%$ NGS, $0.4 \%$ TX solution in PBS followed by incubation in 1\% NGS, $0.04 \%$ TX in PBS containing pCREB (1:1000; Upstate) or CREB1 (1:2000; Upstate) rabbit polyclonal antibody for $48 \mathrm{~h}$ at $4^{\circ} \mathrm{C}$.

Sections were next washed four times with PBS for $15 \mathrm{~min}$ each prior to $1 \mathrm{~h}$ incubation in biotinylated goat anti-rabbit secondary antibody (1:400 in 1\% NGS, 0.2\% TX in PBS; Santa Cruz).
Sections were washed again in PBS three times for 5 min each and then processed with avidin-biotinylated horseradish peroxidase complex in PBS (Elite Kit, Vector Laboratories) for $45 \mathrm{~min}$ at room temperature. Sections were washed four times for $15 \mathrm{~min}$ each in PBS, and the reaction was visualized using diaminobenzidine (DAB Substrate Kit, Vector Laboratories). The reaction was stopped by three 10-min washes in cold $0.01 \mathrm{M}$ PBS, and then sections were mounted on gelatin-coated slides, allowed to dry overnight, and cover-slipped.

\section{Defining regions of interest}

The principal cell layers within the hippocampal formation were identified from coronal sections (according to Paxinos and Watson 1998). The dorsal hippocampal cell counts were taken from coronal sections ranging from $-3.60 \mathrm{~mm}$ to $-3.80 \mathrm{~mm}$ relative to bregma, and ventral hippocampal counts were taken from the coronal sections ranging from $-4.80 \mathrm{~mm}$ to $-6.00 \mathrm{~mm}$ relative to bregma. The pyramidal cell layer of areas CA1 and CA3 and the granule cell layer of the dentate gyrus (DG) were quantified in both the dorsal and ventral hippocampus (Fig. 8). For each brain region analyzed, areas measured across all treatment groups were identical in size in order to standardize measurements.

\section{Quantification of CREB- and pCREB-immunoreactive cells}

Sections were imaged using a Leica DM 6000B/CTR6000 light microscope and a Leica DFC350 FX video camera, which was interfaced to an EP PC computer. This system was used in conjunction with Leica Application Suite for image acquisition and Scion Image software for cell count quantification. A $10 \times$ objective was used to capture all images. Tissue sections were imaged and analyzed using a modification of the procedure established previously (Brown et al. 1998; Countryman et al. 2005). The immunostained cells were optimized using the density slice feature of Scion Image. Cell counts were taken within the defined regions using a particle range from four to 80 pixels depending on cell field being measured. Figure 8 demonstrates sample quantification regions.

\section{Western blots}

Tissue preparation

Following an immediate test for food preference, rats (10 trained young, 10 trained aged, seven cage-control young, seven cage-
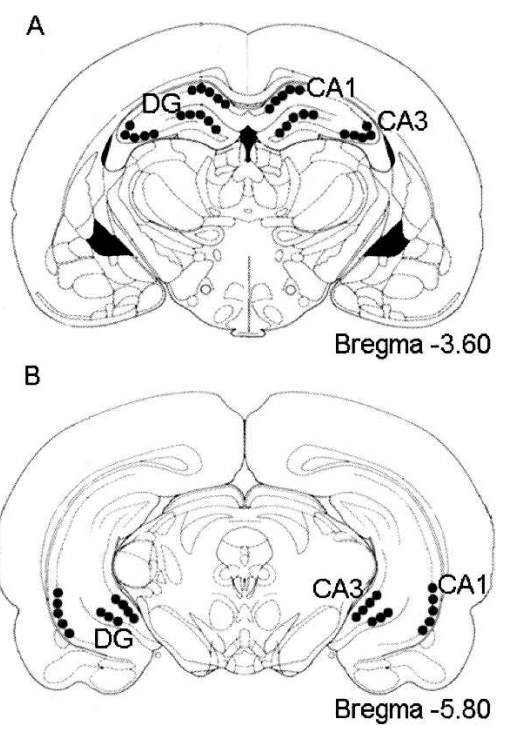

Figure 8. Representation of areas sampled within the dorsal $(A)$ and ventral (B) hippocampus (adapted from Paxinos and Watson 1998). Samples were taken from the pyramidal cell layers of areas CA1, CA3, and the granular cell layer of the dentate gyrus (DG) for both the dorsal and ventral hippocampus. 
control aged) were quickly anesthetized with halothane and decapitated. Bilateral hippocampal dissection was performed on a chilled glass stage. The entire hippocampus was removed (Glowinski and Iverson 1966) and divided into dorsal and ventral portions. The tissue was weighed and homogenized in five volumes of Tris- $\mathrm{HCl}$ membrane buffer containing $0.25 \mathrm{M}$ sucrose, $2 \mathrm{mM}$ EDTA, $10 \mathrm{mM}$ EGTA, $5 \mathrm{mM}$ dithiothreitol, $0.234 \mathrm{mM}$ leupeptin, and $1 \mathrm{mM}$ PMSF as described previously (Brightwell et al. 2004). A fraction of the total homogenate $(25 \mu \mathrm{L})$ was removed to measure total protein concentrations (Bradford 1976). The remaining homogenate was mixed (1:1) with $2 \times$ Laemmli sample buffer (0.2 M SDS, 20\% glycerol, 10\% $\beta$-mercaptoethanol, $0.004 \%$ bromophenol blue, and $1.5 \%$ Tris). The samples were boiled for $5 \mathrm{~min}$ and stored at $-20^{\circ} \mathrm{C}$ until Western blot analyses.

\section{Analyses}

Whole-tissue homogenates from individual rats were normalized by total protein content through dilution with a 1:1 mixture of $2 \times$ sample buffer:running buffer. Normalized total homogenate $(15 \mu \mathrm{g} / 25 \mu \mathrm{L})$ was resolved on $10 \%$ SDS polyacrylamide gels in triplicate and transferred electrophoretically overnight at $4^{\circ} \mathrm{C}$ to Immobilon-P transfer membranes (Millipore). Membranes were washed three times for 5 min each in 0.1 M PBS ( $\mathrm{pH}$ 7.4), blocked three times for 15 min each in $0.1 \mathrm{M}$ PBS containing 5\% nonfat dry milk (NFDM) and $0.03 \%$ Tween 20 , and incubated in primary antibody for CREB for $1.5 \mathrm{~h}$ (1:1000; Upstate). This was followed by three more PBS and NFDM-Tween PBS washes, and a 1.5-h incubation in goat anti-rabbit secondary antibody conjugated to horseradish peroxidase (1:10,000; Kierkegard and Perry Laboratories). Following the secondary antibody incubation, the membranes were washed 15 times for 6 min each in 1\% Tween 20/0.1 M PBS. All incubations and washes were conducted at room temperature on a slow rocker. Immunoreactive bands were visualized with the ECL enhanced chemiluminescence kit (Amersham Pharmacia Biotech) and filmed using Kodak Scientific imaging film X-OMAT.

\section{Densitometry}

X-OMAT films were scanned into a computer, and densitometric analyses were performed using Scion Image. Relative amounts of CREB were determined by regression analysis from a standard curve $(5-25 \mu \mathrm{g})$ prepared from known concentrations of total protein from naïve animals (Colombo et al. 1997).

\section{Data analyses}

Behavioral data were analyzed using repeated measure ANOVAs. The immunocytochemistry results were evaluated by ANOVAs for CREB and PCREB in each of six regions of interest, including dentate gyrus, CA3, and CA1 in both dorsal and ventral hippocampus. After the ANOVAs, planned comparisons were made of young untrained versus old untrained, young trained versus old trained, young untrained versus trained, and old untrained versus trained. For Western blots, CREB and pCREB protein levels were analyzed by ANOVAs for dorsal and ventral hippocampus.

\section{Acknowledgments}

This work was supported by National Institutes of Health Grants from NIA (AG 07648) and NIDA (DA 16951). We thank Alexandra Bass, Danuta Dukala, and Cathy Kowalczyk for their technical assistance.

\section{References}

Alvarez, P., Wendelken, L., and Eichenbaum, H. 2002. Hippocampal formation lesions impair performance in an odor-odor association task independently of spatial context. Neurobiol. Learn. Mem. 78: $470-476$.

Apergis-Schoute, A.M., Debiec, J., Doyere, V., LeDoux, J.E., and Schafe, G.E. 2005. Auditory fear conditioning and long-term potentiation in the lateral amygdala require ERK/MAP kinase signaling in the auditory thalamus: A role for presynaptic plasticity in the fear system. J. Neurosci. 25: 5730-5739.

Asanuma, M., Nishibayashi, S., Iwata, E., Kondo, Y., Nakanishi, T., Vargas, M., and Ogawa, N. 1996. Alterations in cAMP response element-binding activity in the aging rat brain in response to administration of rolipram, a cAMP-specific phosphodiesterase inhibitor. Brain Res. Mol. Brain Res. 41: 210-215.

Barnes, C.A. 1979. Memory deficits associated with senescence: a neurophysiological and behavioral study in the rat. J. Comp. Physiol. Psychol. 93: 74-104.

Barnes, C.A. and McNaughton, B.L. 1985. An age comparison of the rates of acquisition and forgetting of spatial information in relation to long-term enhancement of hippocampal synapses. Behav. Neurosci. 99: 1040-1048.

Bekinschtein, P., Cammarota, M., Igaz, L.M., Bevilaqua, L.R.M., Izquierdo, I., and Medina, J.H. 2007. Persistence of long-term memory storage requires a late protein synthesis- and BDNF-dependent phase in the hippocampus. Neuron 53: 261-277.

Bernabeu, R., Bevilaqua, L., Ardenghi, P., Bromberg, E., Schmitz, P., Bianchin, M., Izquierdo, I., and Medina, J.H. 1997. Involvement of hippocampal cAMP/cAMP-dependent protein kinase signaling pathways in a late memory consolidation phase of aversively motivated learning in rats. Proc. Natl. Acad. Sci. 94: 7041-7046.

Bilang-Bleuel, A., Rech, J., De Carli, S., Holsboer, F., and Reul, J.M. 2002. Forced swimming evokes a biphasic response in CREB phosphorylation in extrahypothalamic limbic and neocortical brain structures in the rat. Eur. J. Neurosci. 15: 1048-1060.

Bradford, M.M. 1976. A rapid and sensitive method for the quantification of microgram quantities of protein utilizing the principle of protein-dye binding. Anal. Biochem. 72: 248-254.

Brightwell, J.J., Gallagher, M., and Colombo, P.J. 2004. Hippocampal CREB1 but not CREB2 is decreased in aged rats with spatial memory impairments. Neurobiol. Learn. Mem. 81: 19-26.

Brightwell, J.J., Smith, C.A., Countryman, R.A., Neve, R.L., and Colombo, P.J. 2005. Hippocampal overexpression of mutant CREB blocks long-term, but not short-term memory for a socially transmitted food preference. Learn. Mem. 12: 12-17.

Brown, H.E., Garcia, M.M., and Harlan, R.E. 1998. A two focal plane method for digital quantification of nuclear immunoreactivity in large brain areas using NIH-image software. Brain Res. Brain Res. Protoc. 2: 264-272.

Bunsey, M. and Eichenbaum, H. 1995. Selective damage to the hippocampal region blocks long term retention of a natural and nonspatial stimulus-stimulus association. Hippocampus 5: 546-556.

Burton, S., Murphy, D., Qureshi, U., Sutton, P., and O'Keefe, J. 2000. Combined lesions of hippocampus and subiculum do not produce deficits in a nonspatial social olfactory memory task. J. Neurosci. 20: 5468-5475.

Clark, R.E., Broadbent, N.J., Zola, S.M., and Squire, L.R. 2002. Anterograde amnesia and temporally graded retrograde amnesia for a nonspatial memory task after lesions of hippocampus and subiculum. J. Neurosci. 22: 4663-4669.

Colombo, P.J., Wetsel, W.C., and Gallagher, M. 1997. Spatial memory is related to hippocampal subcellular concentrations of calcium-dependent protein kinase $\mathrm{C}$ isoforms in young and aged rats. Proc. Natl. Acad. Sci. 94: 14195-14199.

Countryman, R.A., Orlowski, J.D., Brightwell, J.J., Oskowitz, A.Z., and Colombo, P.J. 2005. CREB phosphorylation and c-fos expression in the hippocampus of rats during acquisition and recall of a socially transmitted food preference. Hippocampus 15: 56-67.

Dash, D.K., Hochner, B., and Kandel, E.R. 1990. Injection of the cAMP-response element into the nucleus of Aplysia sensory neurons blocks long-term facilitation. Nature 345: 718-721.

Dineley, K.T., Westerman, M., Bui, D., Bell, K., Ashe, K.H., and Sweatt, J.D. 2001. $\beta$-Amyloid activates the mitogen-activated protein kinase cascade via hippocampal a7 nicotinic acetylcholine receptors: In vitro and in vivo mechanisms related to Alzheimer's disease. J. Neurosci. 21: 4125-4133.

Disterhoft, J.F., Moyer Jr., J.R., and Thompson, L.T. 1994. The calcium rationale in aging and Alzheimer's disease. Evidence from an animal model of normal aging. Ann. N. Y. Acad. Sci. 747: 382-406.

Foster, T.C. 1999. Involvement of hippocampal synaptic plasticity in age-related memory decline. Brain Res. Brain Res. Rev. 30: 236-249.

Foster, T.C., Sharrow, K.M., Masse, J.R., Norris, C.M., and Kumar, A. 2001. Calcineurin links $\mathrm{Ca}^{2+}$ dysregulation with brain aging. J. Neurosci. 21: 4066-4073.

Frankland, P.W., Josselyn, S.A., Anagnostaras, S.G., Kogan, J.H., Takahashi, E., and Silva, A.J. 2004. Consolidation of CS and US representations in associative fear conditioning. Hippocampus 14: $557-569$.

Gage, F.H., Dunnett, S.B., and Bjorklund, A. 1984. Spatial learning and motor deficits in aged rats. Neurobiol. Aging 5: 43-48. 
Galef Jr., B.G. and Whiskin, E.E. 2003. Socially transmitted food preference can be used to study long-term memory in rats. Learn. Behav. 31: 160-164.

Gallagher, M. and Nicolle, M.M. 1993. Animal models of normal aging: Relationship between cognitive decline and markers in hippocampal circuitry. Behav. Brain Res. 57: 155-162.

Gallagher, M. and Rapp, P.R. 1997. The use of animal models to study the effects of aging on cognition. Annu. Rev. Psychol. 48: 339-370.

Gallagher, M., Burwell, R., and Burchinal, M. 1993. Severity of spatial learning impairment in aging: Development of a learning index for performance in the Morris water maze. Behav. Neurosci. 107: 618626.

Gass, P., Wolfer, D.P., Balschun, D., Rudolph, D., Frey, U., Lipp, H.P., and Schutz, G. 1998. Deficits in memory tasks of mice with CREB mutations depend on gene dosage. Learn. Mem. 5: 274-288.

Glowinski, J. and Iverson, L.L. 1966. Regional studies of catecholamines in the rat brain. I. The disposition of $\left[{ }^{3} \mathrm{H}\right]$ norepinephrine, $\left[{ }^{3} \mathrm{H}\right]$ dopamine, and $\left[{ }^{3} \mathrm{H}\right]$ dopa in various regions of the brain. J. Neurochem. 50: 1364-1368.

Goelet, P., Castellucci, V.F., Schacher, S., and Kandel, E.R. 1986. The long and the short of long-term memory-A molecular framework. Nature 322: 419-422.

Gold, P.E. 2001. Drug enhancement of memory in aged rodents and humans. In Animal research and human health: Advancing human welfare through behavioral science (eds. M.E. Carroll and J.B. Overmier), pp. 293-304. American Psychological Association, Washington, DC.

Gold, P.E. 2005. Glucose and age-related changes in memory. Neurobiol. Aging 26S: S60-S64.

Gold, P.E. 2006. The many faces of amnesia. Learn. Mem. 13: 506-514.

Gold, P.E., McGaugh, J.L., Hankins, L.L., Rose, R.P., and Vasquez, B.J. 1982. Age dependent changes in retention in rats. Exp. Aging Res. 8: $53-58$.

Gower, A.J. and Lamberty, Y. 1993. The aged mouse as a model of cognitive decline with special emphasis on studies in NMRI mice. Behav. Brain Res. 57: 163-173.

Guzowski, J.F. and McGaugh, J.L. 1997. Antisense oligodeoxynucleotide-mediated disruption of hippocampal cAMP response element binding protein levels impairs consolidation of memory for water maze training. Proc. Natl. Acad. Sci. 94: 26932698.

Guzowski, J.F., Lyford, G.L., Stevenson, G.D., Houston, F.P., McGaugh, J.L., Worley, P.F., and Barnes, C.A. 2000. Inhibition of activity-dependent arc protein expression in the rat hippocampus impairs the maintenance of long-term potentiation and the consolidation of long-term memory. J. Neurosci. 20: 3993-4001.

Houpt, T.A. and Berlin, R. 1999. Rapid, labile, and protein synthesis-independent short-term memory in conditioned taste aversion. Learn. Mem. 6: 37-46.

Huang, Y.-Y., Li, X.-C., and Kandel, E.R. 1994. cAMP contributes to mossy fiber LTP by initiating both a covalently mediated early phase and macromolecular synthesis-dependent late phase. Cell 79: 69-79.

Impey, S., Mark, M., Villacres, E.C., Poser, S., Chavkin, C., and Storm, D.R. 1996. Induction of CRE-mediated gene expression by stimuli that generate long-lasting LTP in area CA1 of the hippocampus. Neuron 16: 973-982.

Impey, S., Smith, D.M., Obrietan, K., Donahue, R., Wade, C., and Storm, D.R. 1998. Stimulation of cAMP response element (CRE)-mediated transcription during contextual learning. Nat. Neurosci. 1: 595-601.

Izquierdo, L.A., Barros, D.M., Vianna, M.R., Coitinho, A., deDavid e Silva, T., Choi, H., Moletta, B., Medina, J.H., and Izquierdo, I. 2002. Molecular pharmacological dissection of short- and long-term memory. Cell. Mol. Neurobiol. 22: 269-287.

Kandel, E.R. 2001. The molecular biology of memory storage: A dialogue between genes and synapses. Science 294: 1030-1038.

Kelly, A., Laroche, S., and Davis, S. 2003. Activation of mitogen-activated protein kinase/extracellular signal-regulated kinase in hippocampal circuitry is required for consolidation and reconsolidation of recognition memory. J. Neurosci. 23: 5354-5360.

Kogan, J.H., Frankland, P.W., Blendy, J.A., Coblentz, J., Marowitz, Z., Shutz, G., and Silva, A.J. 1996. Spaced training induces normal long-term memory in CREB mutant mice. Curr. Biol. 7: 1-11.

Kogan, J.H., Frankland, P.W., and Silva, A.J. 2000. Long-term memory underlying hippocampus-dependent social recognition in mice. Hippocampus 10: 47-56.

Korol, D.L. 2002. Enhancing cognitive function across the life span. Ann. N. Y. Acad. Sci. 959: 167-179.

Korol, D.L. and Gold, P.E. 1998. Glucose, memory and aging. Am. J. Clin. Nutr. 67: 764S-771S

Kudo, K., Wati, H., Qiao, C., Arita, J., and Kanba, S. 2005. Age-related disturbance of memory and CREB phosphorylation in CA1 area of hippocampus of rats. Brain Res. 1054: 30-37.
Kunieda, T., Minamino, T., Katsuno, T., Tateno, K., Nishi, J., Miyauchi, H., Orimo, M., Okada, S., and Komuro, I. 2006. Cellular senescence impairs circadian expression of clock genes in vitro and in vivo. Circ. Res. 98: 532-539.

Lamberty, Y. and Gower, A.J. 1992. Age-related changes in spontaneous behavior and learning in NMRI mice from middle $\mathrm{m}$ old age. Physiol. Behav. 51: 81-88.

Lund, P.K., Hoyt, E.C., Bizon, J., Smith, D.R., Haberman, R., Helm, K., and Gallagher, M. 2004. Transcriptional mechanisms of hippocampal aging. Exp. Gerontol. 39: 1613-1622.

Mabry, T.R., McCarty, R., Gold, P.E., and Foster, T.C. 1996. Age and stress history effects on spatial performance in a swim task in Fischer-344 rats. Neurobiol. Learn. Mem. 66: 1-10.

Markowska, A.L., Stone, W.S., Ingram, D.K., Reynolds, J., Gold, P.E., Conti, L.H., Pontecorvo, M.J., Wenk, G.L., and Olton, D.S. 1989. Individual differences in aging: Behavioral and neurobiological correlates. Neurobiol. Aging 10: 31-44.

McGaugh, J.L. 2000. Memory-A century of consolidation. Science 287: $248-251$

Monti, B., Berteotti, C., and Contestabile, A. 2005. Dysregulation of memory-related proteins in the hippocampus of aged rats and their relation with cognitive impairment. Hippocampus 15: 1041-1049.

Paxinos, G. and Watson, C. 1998. The rat brain in stereotaxic coordinates, 4th ed. Academic Press, San Diego, CA.

Petrovich, G.D., Canteras, N.S., and Swanson, L.W. 2001. Combinatorial amygdalar inputs to hippocampal domains and hypothalamic behavior systems. Brain Res. Brain Res. Rev. 38: 247-289.

Quartermain, D. and McEwen, B.S. 1970. Temporal characteristics of amnesia induced by protein synthesis inhibitor: Determination by shock level. Nature 228: 677-678.

Rapp, P.R., Rosenberg, R.A., and Gallagher, M. 1987. An evaluation of spatial information processing in aged rats. Behav. Neurosci. 101: $3-12$.

Roberts, M. and Shapiro, M. 2002. NMDA receptor antagonists impair memory for nonspatial, socially transmitted food preference. Behav. Neurosci. 116: 1059-1069.

Roman, F.S., Alescio-Lautier, B., and Soumireu-Mourat, B. 1996. Age-related learning and memory deficits in odor-reward association in rats. Neurobiol. Aging 17: 31-40.

Ross, R.S. and Eichenbaum, H. 2006. Dynamics of hippocampal and cortical activation during consolidation of a nonspatial memory. I. Neurosci. 26: 4852-4859.

Salinas, J.A. and Gold, P.E. 2005. Glucose regulation of memory for reward reduction in young and aged rats. Neurobiol. Aging 26: 45-52.

Schulz, S., Siemer, H., Krug, M., and Hollt, V. 1999. Direct evidence for biphasic cAMP responsive element-binding protein phosphorylation during long-term potentiation in the rat dentate gyrus in vivo. J. Neurosci. 19: 5683-5692.

Silva, A.J., Kogan, J.H., Frankland, P.W., and Kida, S. 1998. CREB and memory. Annu. Rev. Neurosci. 21: 127-148.

Solomon, P.R., Barth, C.L., Wood, M.S., Velazquez, E., Groccia-Ellison, M., and Yang, B.Y. 1995. Age-related deficits in retention of the classically conditioned nictitating membrane response in rabbits. Behav. Neurosci. 109: 18-23.

Squire, L.R. and Barondes, S.H. 1972. Variable decay of memory and its recovery in cycloheximide-treated mice. Proc. Natl. Acad. Sci. 69: $1416-1420$.

Stanciu, M., Radulovic, J., and Spiess, J. 2001. Phosphorylated cAMP response element binding protein in the mouse brain after fear conditioning: Relationship to Fos production. Brain Res. Mol. Brain Res. 94: 15-24.

Stone, W.S., Rudd, R.J., and Gold, P.E. 1992. Glucose attenuation of deficits in spontaneous alternation behavior and augmentation of relative brain 2-deoxyglucose uptake in old and scopolamine-treated mice. Psychobiology 20: 270-279.

Tang, Y.-P., Shimizu, E., Dube, G.R., Rampon, C., Kerchner, G.A., Zhuo, M., Liu, G., and Tsien, J.Z. 1999. Genetic enhancement of learning and memory in mice. Nature 401: 63-69.

Taubenfeld, S.M., Wiig, K.A., Monti, B., Dolan, B., Pollonini, G., and Alberini, C.M. 2001. Fornix-dependent induction of hippocampal CCAAT enhancer-binding protein $\beta$ and $\delta$ co-localizes with phosphorylated cAMP response element-binding protein and accompanies long-term memory consolidation. J. Neurosci. 21: 84-91.

Thibault, O., Porter, N.M., Chen, K.C., Blalock, E.M., Kaminker, P.G. Clodfelter, G.V., Brewer, L.D., and Landfield, P.W. 1998. Calcium dysregulation in reuronal aging and Alzheimer's disease: History and new directions. Cell Calcium 24: 417-433.

Trifilieff, P., Herry, C., Vanhoutte, P., Caboche, J., Desmedt, A., Riedel, G., Mons, N., and Micheau, J. 2006. Foreground contextual fear memory consolidation requires two independent phases of hippocampal ERK/CREB activation. Learn. Mem. 13: 349-358. 
Wenk, G.L. and Barnes, C.A. 2000. Regional changes in the hippocampal density of AMPA and NMDA receptors across the lifespan of the rat. Brain Res. 885: 1-5.

Winocur, G. 1988. Long-term memory loss in senescent rats: Neuropsychological analysis of interference and context effects. Psychol. Aging 3: 273-279.

Winocur, G. 1990. Anterograde and retrograde amnesia in rats with dorsal hippocampal or dorsomedial thalamic lesions. Behav. Brain Res. 38: $145-154$.

Winocur, G. and Moscovitch, M. 1999. Anterograde and retrograde amnesia after lesions to frontal cortex in rats. J. Neurosci. 19: 96119617.
Winocur, G., McDonald, R.M., and Moscovitch, M. 2001. Anterograde and retrograde amnesia in rats with large hippocampal lesions. Hippocampus 11: 18-26.

Yin, J.C. and Tully, T. 1996. CREB and the formation of long-term memory. Curr. Opin. Neurobiol. 6: 264-268.

Zornetzer, S.F., Thompson, R., and Rogers, J. 1982. Rapid forgetting in aged rats. Behav. Neural Biol. 36: 49-60.

Received January 5, 2007; accepted in revised form March 13, 2007. 


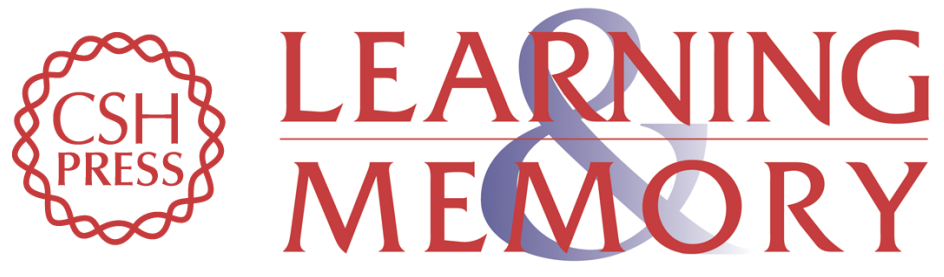

\section{Rapid forgetting of social transmission of food preferences in aged rats: Relationship to hippocampal CREB activation}

Renee A. Countryman and Paul E. Gold

Learn. Mem. 2007, 14:

Access the most recent version at doi:10.1101//m.524907

References This article cites 80 articles, 24 of which can be accessed free at: http://learnmem.cshlp.org/content/14/5/350.full.html\#ref-list-1

License

Email Alerting

Receive free email alerts when new articles cite this article - sign up in the box at the Service top right corner of the article or click here. 